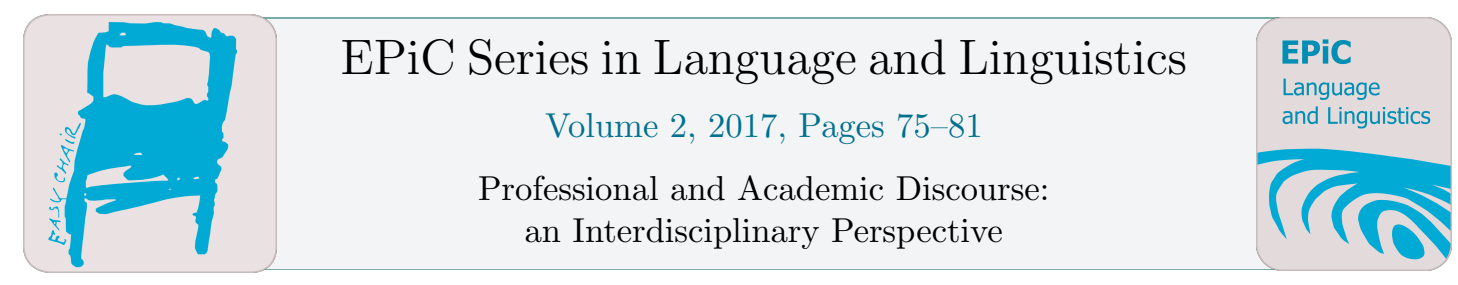

\title{
Proficiency effect on EFL Learners’ realization of complaints
}

\author{
Esther Usó-Juan and Alicia Martínez-Flor \\ Universitat Jaume I, Castellón, Spain \\ euso@ang.uji.es, aflor@ang.uji.es
}

\begin{abstract}
Research on the effect of language proficiency on L2 pragmatics seems to provide somewhat mixed results (Xiao, 2015). On that account, this paper investigates the effect of English language proficiency on English language learner's use of complaining strategies in contrasting situations which varied according to the sociopragmatic factors of social status, social distance and severity of offense. Results show that learners at two proficiency levels demonstrated similar patterns with regard their use of buffer and complaint super-strategies across situations. However, negotiation super-strategies were more frequent across situations in the higher proficiency group. These findings are discussed and pedagogical implications suggested.
\end{abstract}

\section{Introduction}

A major goal in learning a second/foreign language (L2) is to be able to communicate appropriately in the L2, which in turn requires not only mastery over the features of the language system but also over the pragmatic rules of language use. In fact, in cross-cultural communication, failure to do so may lead to unintended offense and communication breakdown. As a result, how learners acquire their pragmatic ability in the L2 has become a major concern in the study of L2 development. Following Thomas (1983), pragmatic knowledge is comprised of two components: pragmalinguistic competence (i.e. the ability to choose appropriate linguistic expressions) and sociopragmatic competence (i.e. the ability to evaluate context taking into account: i) the culture involved, ii) the relative age and gender of the interlocutors, iii) their social class and occupations, and iv) their roles and status in the interaction. In order to foster pragmatic competence, learners not only need to develop practice connecting form and meaning, but also they need to account for the rules that govern the use of language in context.

This paper, therefore, is concerned with the development of one aspect of pragmatic knowledge, namely, the ability to make complaints in the interlanguage of Spanish learners of English because of the unique characteristics of this kind of speech. The speech act of complaining has been defined as an expressive illocutionary act "in which the speaker (the complainer) expresses his/her disapproval, negative feelings etc. towards the state of affairs described in the proposition (the complainable) and for which he/she holds the hearer (the complainee) responsible” (Trosborg, 1995: 311-312). This act 
thus, is inherently face-threatening according to Brown and Levinson's (1987) politeness theory. In the light of their distinction between positive and negative face, a complaint threatens the hearer's positive face as it goes against a person's wish to be liked or appreciated by others. Moreover, it may also threaten the hearer's negative face of being free from imposition, when a complaint is accompanied by a request for compensation.

Due to the face-threatening nature a complaint entails, the speaker needs to control the different directness levels at which he/she is going to perform the complaint. Indeed, a complainer will compute the weightiness of this face-threatening act based on three parameters: i) the relative social status of the interlocutors, ii) the social distance between them (Brown and Levinson, 1987), as well as iii) the level of offense involved in the complaint being performed (Olshtain and Weinbach, 1987). These social variables play an important role in the speakers' decision on the directness of complaints. As a consequence, to complain appropriately and in a socially accepted manner the complainer must carefully assess these three criteria and then vary the strategy use according to the contextual requirements to minimise the face threat.

Previous studies on complaints have typically examined how learners produce complaints in their interlanguage in comparison to English native speakers' (NSs) performance. Research documenting this fact involves learners from different backgrounds, namely, Danish (Trosborg, 1995), Korean (Murphy and Neu, 1996), Thai (Rhurakvit, 2011), Indonesian (Da Silva, 2014) or mixed first language backgrounds (Moon, 2001; Tanck, 2002). Overall, qualitative and quantitative differences in the use of semantic formulas to perform a complaint have been found. These cross-cultural studies are important not only for describing how English NSs perform complaints in daily interactions, but also for the purpose of making a baseline of information in instructional contexts.

However, as claimed by Kasper and Smith (1996), in order to have more insights on the development of pragmatic competence research on learner-based factors is needed. Among the factors examined, L2 proficiency has been a popular factor since it has been regarded as a precondition of pragmatic competence (Xiao, 2015). Research on the effect of language proficiency on L2 pragmatics seems to provide somewhat mixed results. On the one hand, Hong and Shih (2011) showed that advanced learners tend to manage more appropriate levels of directness in speech acts and use more target-like expressions, and thus approximate to native-like performance. Similarly, Al-Gahtani and Roever (2012) reported that more proficient learners had a better pragmatic performance at the discourse level, such as sequential organisation. On the other hand, Trosborg (1995) found that the L2 learners' pragmatic ability is not proportional to their English language proficiency and pointed out that even advanced learners lack the necessary L2 pragmatic knowledge. In order to shed more light on these mixed results, the present study investigates the effect of English language proficiency on Spanish-speaking English language learners' use of complaining strategies in contrasting situations.

\section{Methodology}

Participants taking part in our study consisted of 16 female Spanish learners* of English who were second-year students of the degree of English Studies at the University. Subjects' age ranged between 19 and 22 years old. To comply with the purposes of the study, the participants formed two English proficiency groups based on their scores on the Quick Placement Test (2001): Lower-Intermediate students $(\mathrm{N}=8)$, which would correspond to level $\mathrm{B} 1$, and Upper-Intermediate students $(\mathrm{N}=8)$, which would correspond to level B2 (Council of Europe).

\footnotetext{
* There were a total of 32 learners participating in the study. However, since learners were paired and required each to perform the role of a complainer or apologizer for the production task, we just analysed data from those 16 learners performing as complainers.
} 
Learner's production of complaints was elicited by means of an Interactive Discourse Completion Test (IDCT) adopted from Usó-Juan and Martínez-Flor (2014), as it is closer to naturally occurring events. The test set involved two tasks each including a scenario for a complaint and an apology. However, for the purposes of the present study, we focus only on complaints. Three contextual variables served to create the two social situations used in the two tasks: social status (S), social distance (D), and severity of offense $(\mathrm{O})$. These three variables served to dichotomise the two tasks into two situation types: SDO-high and SDO-low. In the SDO-high task, the complainer had a low social status, the interlocutor distance was large, and the degree of imposition was large. In the SDO-low task, the complainer had a high social status, the interlocutor distance was small and the degree of imposition was small. In those situations students had to orally interact as in a role-play and write what they would actually say. The IDCT was administered by the learners' lecturer during in-class time. Table 1 displays simplified situations.

\begin{tabular}{l|l|l}
\hline Situation type & Interlocutors & Scenario topic \\
\hline SDO-high & $\begin{array}{l}\text { group leader vs. } \\
\text { hotel manager }\end{array}$ & $\begin{array}{l}\text { Your hotel reservation for a group of 20 people has } \\
\text { been lost. }\end{array}$ \\
\hline SDO-low & $\begin{array}{l}\text { general manager vs. } \\
\text { personal assistant }\end{array}$ & $\begin{array}{l}\text { Your personal assistant handed in to you a business } \\
\text { document with a few misspelled words. }\end{array}$ \\
\hline
\end{tabular}

Table 1: Simplified eliciting scenarios used in the IDCT.

Complaints were identified in the IDCT data and classified into different complaint super-strategies and sub-strategies based on a coding system adopted from Olshtain and Weinbach (1987), Trosborg (1995) and Rhurakvit (2011) (see Table 2). The super-strategy of buffer, following Rhurakvit (2011), is regarded as an optional statement used to diminish the severity of the complaint. It can be found throughout the message; however, it is normally used at the beginning or at the end of the utterance or in both places. The super-strategy of complaint, following Olshtain and Weinbach (1987) and Trosborg (1995), can be realised in five different ways. These five options are presented on a scale that depends on the severity of the complaint ranging from the least (C1) to the most severe (C5). Finally, the superstrategy of negotiation, following Rhurakvit (2011), is also an optional element used to negotiate a remedy from the offender. It may be used alone or combined with the super-strategy of complaint, either preceding or following it.

Grammatical accuracy was not taken into account in the data analysis process and complaint strategies were coded as long as they were unequivocally understood by the researchers. 


\begin{tabular}{|c|c|c|}
\hline $\begin{array}{l}\text { Super- } \\
\text { Strategies }\end{array}$ & Sub-Strategies & Examples \\
\hline \multicolumn{3}{|l|}{$\begin{array}{l}\text { Buffer } \\
\text { [B] }\end{array}$} \\
\hline & $\begin{array}{l}\text { B1. Apologising } \\
\text { B2. Complimenting } \\
\text { B3. Greeting } \\
\text { B4. Thanking } \\
\text { B5. Provision of Context }\end{array}$ & $\begin{array}{l}\text { Sorry, Excuse me. } \\
\text { Emma is a good cleaner. } \\
\text { Hi, Hello. } \\
\text { Thanks, Thanks a lot. } \\
\text { I actually ordered two dishes of well-done } \\
\text { T-bone steaks but... }\end{array}$ \\
\hline Complaint [C] & $\begin{array}{l}\text { C1. No explicit reproach } \\
\text { C2. Expression of disapproval } \\
\text { C3. Explicit complaint } \\
\text { C4. Expression of accusation / } \\
\text { warning } \\
\text { C5. Expression of threat }\end{array}$ & $\begin{array}{l}\text { Never mind, nothing serious happened. } \\
\text { What terrible bureaucracy! } \\
\text { You're always late. } \\
\text { I'll speak to your supervisor. } \\
\text { I'm not moving one inch unless you } \\
\text { change my appointment. }\end{array}$ \\
\hline Negotiation [N] & $\begin{array}{l}\text { N1. Suggestion } \\
\text { N2. Request for Repair }\end{array}$ & $\begin{array}{l}\text { You should be punctual next time. } \\
\text { Could you please keep your voice down? }\end{array}$ \\
\hline
\end{tabular}

Table 2: Coding framework of complaints.

\section{Results and Discussion}

The analysis of the 32 complaint samples (16 participants x 2 situations $\mathrm{x} 1$ IDCT) yielded a total of 168 complaint strategies. Of these, 79 were identified in the lower-intermediate group data and 89 in the upper-intermediate group data. As can be seen in Table 3, for both groups the buffer was the most selected super-strategy (63.3\% in the lower group and 53.9\% in the upper group), followed by the complaint (29.1\% in the lower group and $27.0 \%$ in the upper group), and then the negotiation (7.6\% in the lower group and $19.1 \%$ in the upper group). Both groups of learners produced across scenarios a rather similar number of buffers and complaints. However, negotiations were more frequent in the upper-intermediate group. Language proficiency therefore, played a role in determining the number of sub-strategies of negotiation, but no with regard to the production of buffers or complaints. These findings seem to indicate, in line with Al-Gahtani and Roever's (2012) study that higher proficiency learners had better performance at the discourse level, but their sensitivity to the parameters of status, social distance and imposition in target situations was similar to that of lower proficiency learners.

\begin{tabular}{|c|c|c|c|c|c|c|c|}
\hline \multirow{3}{*}{$\begin{array}{r}\text { Complaint } \\
\text { categories }\end{array}$} & \multicolumn{3}{|c|}{ Lower-Intermediate } & \multicolumn{3}{|c|}{ Upper-Intermediate } & \multirow[t]{2}{*}{ Total } \\
\hline & SDO-high & SDO-low & Sub-total & SDO-high & SDO-low & Sub-total & \\
\hline & $f(\%)$ & $f(\%)$ & $f(\%)$ & $f(\%)$ & $f(\%)$ & $f(\%)$ & $f(\%)$ \\
\hline Buffer & $26(63.4)$ & $24(63.2)$ & $50(63.3)$ & $25(55.6)$ & $23(52.3)$ & 48 (53.9) & 98 (58.3) \\
\hline Complaint & 11 (26.9) & 12 (31.6) & $23(29.1)$ & $12(26.6)$ & $12(27.3)$ & $24(27.0)$ & 47 (28.0) \\
\hline Negotiation & $4(9.7)$ & $2(5.2)$ & $6(7.6)$ & $8(17.8)$ & $9(20.4)$ & $17(19.1)$ & 23 (13.7) \\
\hline Total & $41(100.0)$ & $38(100.0)$ & $79(100.0)$ & $45(100.0)$ & $44(100.0)$ & $89(100.0)$ & $168(100.0)$ \\
\hline
\end{tabular}

Table 3: Frequencies and percentages of complaint super-strategies across scenarios. Note: Percentages are rounded to one decimal. 
A detailed analysis of the different complaint sub-strategies employed within each complaint category across scenarios appears to indicate that the distribution of use was similar among the two proficiency groups (see Table 4). Starting with responses to the SOD-high situation, both groups applied the buffer sub-strategies in a similar way. It was found that provision of context (34.6\% in the lower group and $40.0 \%$ in the upper group), thanking (34.6\% in the lower group and $24.0 \%$ in the upper group) and greeting (30.8 in the lower group and $28.0 \%$ in the upper group) were the most consistently employed strategies by both groups.

Regarding the complaint, the explicit complaint was the sub-strategy selected most frequently by both groups (54.5\% in the lower group and 66.6\% in the upper group). Other sub-strategies that were used much less frequently included: expression of disapproval (27.3\% in the lower group and $16.7 \%$ in the upper group), expression of threat (9.1\% in the lower group and $16.7 \%$ in the upper group) and expression of accusation and warning (9.1\% in the lower group and no instances of strategies in the upper group). Finally, with respect to the sub-strategies of negotiation, the request for repair was selected in all situations by the lower group (100\%), while the upper group used request for repair (87.5\%) but also suggestion (12.5\%).

\begin{tabular}{c|c|c|c|c}
\hline \multirow{2}{*}{ Strategies } & \multicolumn{2}{|c|}{ Lower-Intermediate } & \multicolumn{2}{c}{ Upper-Intermediate } \\
\cline { 2 - 5 } & SDO-high & SDO-low & SDO-high & SDO-low \\
\cline { 2 - 5 } Buffer & $f(\%)$ & $f(\%)$ & $f(\%)$ & $f(\%)$ \\
\hline Apologising & & & & \\
\hline Complimenting & 0 & 0 & $1(4.0)$ & 0 \\
\hline Greeting & 0 & $6(25.0)$ & $1(4.0)$ & $6(26.1)$ \\
\hline Thanking & $8(30.8)$ & $6(25.0)$ & $7(28.0)$ & $8(34.8)$ \\
\hline Provision of context & $9(34.6)$ & $4(16.7)$ & $6(24.0)$ & $3(13.0)$ \\
\hline Total percentage of buffers & $9(34.6)$ & $8(33.3)$ & $10(40.0)$ & $6(26.1)$ \\
\hline Complaint & $26(100.0)$ & $24(100.0)$ & $25(100.0)$ & $23(100.0)$ \\
\hline No explicit reproach & & & & 0 \\
\hline Disapproval & $3(27.3)$ & 0 & 0 & 0 \\
\hline Explicit complaint & $6(54.5)$ & $9(75.0)$ & $8(66.6)$ & $9(75.0)$ \\
\hline Accusation/warning & $1(9.1)$ & $3(25.0)$ & 0 & 0 \\
\hline Threat & $1(9.1)$ & 0 & $2(16.7)$ & $1(8.3)$ \\
\hline Total percentage of complaints & $11(100.0)$ & $12(100.0)$ & $12(100.0)$ & $12(100.0)$ \\
\hline Negotiation & \multicolumn{3}{|c|}{} & \\
\hline Suggestion & 0 & $1(50.0)$ & $1(12.5)$ & $4(44.4)$ \\
\hline Request for Repair & $4(100.0)$ & $1(50.0)$ & $7(87.5)$ & $5(55.6)$ \\
\hline Total percentage of negotiations & $4(100.0)$ & $2(100.0)$ & $8(100.0)$ & $9(100.0)$ \\
\hline
\end{tabular}

Table 4: Frequencies and percentages of complaint sub-strategies across scenarios $(n=168)$.

Note: Percentages are rounded to one decimal.

Moving to responses to the SOD-low situation, both groups tended to select the same buffer substrategies. It appears that provision of context (33.3\% in the lower group and $26.1 \%$ in the upper group), greeting (25.0\% in the lower group and $34.8 \%$ in the upper group) and complimenting (25.0\% in the lower group and $26.1 \%$ in the upper group) were selected most frequently by the two groups. Apart from these three strategies, learners also used thanking (16.7\% in the lower group and $13.0 \%$ in the upper group). As it happened with responses to the SOD-high situation, greeting and provision of content were also frequently opted for. In contrast, however, in the SOD-low situation, both learner groups increased the frequency of complimenting and decreased the frequency of thanking. Complimenting has been regarded as an indirect thanking strategy and this fact could explain this behavioral pattern. Thus, these findings show that all learners, regardless of proficiency level, were able to switch their speech behavior according to context. 
With regard to the use of the complaint, it appears that the explicit complaint was by far the most frequently used by both groups (75.0\% in the lower group and upper group). Apart from this substrategy, the expression of accusation and warning was also employed by the lower group (25.0\%) whereas the upper group employed expression of disapproval (16.7\%) and expression of threat (8.3\%). When the distributions of complaint sub-strategies are compared across scenarios, it appears that learners, regardless of proficiency level, showed a preference for the explicit complaint formula and therefore, they did not adjust their performance sufficiently to the parameters of status, social distance and imposition. Thus, increased proficiency did not improve the performance of complaints, which are complex in nature and do not have a fixed pragmalinguistic form. These results are in line with Trosborg's (1995) study, which showed that even advanced learners were unable to adjust their performance to different contrasting contexts. Similarly, the studies conducted by Moon (2001) and Tank (2002) found that learners had a tendency to make explicit and direct complaints while NSs preferred implicit complaints in situations which varied according to the parameters of power, distance and weight of imposition (Moon, 2001) or power (Tank, 2002) and therefore, suggested formal instruction on the use of other complaint formulas to speed up their acquisition.

Lastly, with respect to the sub-strategies of negotiation, it is noticed that request for repair ( $50 \%$ in the lower group and 55.6\% in the upper group) and suggestion (50\% in the lower group and $44.4 \%$ in the upper group) were used by both groups. Interestingly, as it ocurred with responses to the SOD-high situation, it is important to note that the higher group was more likely to negotiate a complaint across scenarios compared to the lower group, who barely used the negotiation sub-strategies. Following Xiao's (2015) suggestions, a possible explanation of these results could be that higher proficiency learners had more knowledge of fixed pragmalinguistic forms to perform the conventional acts of requesting and suggesting, whereas lower proficiency learners had a limited knowledge of those formulas.

\section{Conclusion}

The purpose of this study was to analyse the proficiency-level effect on learners' choice of the strategies to construct complaints in contrasting situations which varied according to the sociopragmatic factors of social status, distance and imposition. Results have shown that on the whole, the two proficiency groups demonstrated similar patterns with regard their use of buffer and complaint superstrategies across contrasting situations, since they all employed a high number of buffers to mitigate the complaint and tended to use the explicit complaint formula. However, negotiations were more frequent across situations in the upper-intermediate group, possibly due to learners' familiarity with the fixed pragmalinguistic formulas to perform conventionalised requests and suggestions. This study, therefore points to an interesting pedagogical implication, since learners, regardless of their proficiency level, should be made aware through pedagogical-oriented activities of all strategies used to express complaints (i.e. pragmalinguistic competence), and those contexts in which these pragmalinguistic strategies are appropriately used (i.e. sociopragmatic competence). In this sense, we believe that the complaint strategies presented in this study (see Table 2 above) could facilitate teachers' intervention on complaints adopting a discursive approach. 


\section{Notes}

As members of the LAELA (Lingüística Aplicada a l’Ensenyament de la Llengua Anglesa) research group, we would like to acknowledge that this study is part of a research project funded by the Spanish Ministerio de Economía y Competitividad (FFI2012-38145).

\section{References}

Al-Gahtani, S. and Roever, C. (2012). Proficiency and sequential organization of L2 requests. Applied Linguistics, 33(1), 42-65.

Brown, P. and Levinson, S. (1987). Politeness: Some universals in language usage. Cambridge: Cambridge University Press.

Da Silva, A.M. (2014). Analyzing complaints by Indonesian EFL Speakers. Culture, English Language Teaching and Literature, 14(1), 63-81.

Hong, Ch. and Shih, S. (2011). Proficiency and complaints: Analyses of productions and perceptions. Intergrams, 14(1).

Kasper, G. and Schmidt, R. (1996). Developmental issues in interlanguage pragmatics. Studies in Second Language Acquisition, 18(2), 149-169.

Moon, K. (2002). Speech Act Study: Differences Between Native and Nonnative Speaker Complaint Strategies. Available at https://american.edu/cas/tesol/pdf/upload/WP-2002-Moon-Speech-Act.pdf

Murphy, B. and Neu, J. (1996). My grade's too low: The speech act set of complaining. In S. M. Gass and J. Neu (Eds.), Speech acts across cultures: Challenges to communication in a second language (pp. 191-216). Berlin: Mouton de Gruyter.

Olshtain, E. and Weinbach, L. (1987). Complaints: A study of speech act behaviour among native and nonnative speakers of Hebrew. In J. Verschueren and M. Bertuccelli-Papi (Eds.), The pragmatic perspective: Selected papers from the 1985 International Pragmatics Conference (pp. 195-208). Amsterdam: John Benjamins.

Quick Placement Test (2001). Paper and Pen Test. Oxford: Oxford University Press.

Rhurakvit, M. (2011). Complaints in Thai and English: An interlanguage pragmatic study. London: Queen Mary University.

Tanck, S. (2002). Speech Act Sets of Refusal and Complaint: A Comparison of Native and NonNative English Speakers' Production. Paper, American University, Department of TESL, Washington D.C.

Thomas, J. (1983). Cross-cultural pragmatic failure. Applied Linguistics, 4(2), 91-109.

Trosborg, A. (1995). Interlanguage pragmatics: Requests, complaints and apologies. Berlin: Mouton de Gruyter.

Usó-Juan, E. and Martínez-Flor, A. (2014). Reorienting the assessment of the conventional expressions of complaining and apologising: From single-response to interactive DCTs. Iranian Journal of Language Testing, 4(1), 113-136.

Xiao, F. (2015). Proficiency effect on L2 pragmatic competence. Studies in Second Language Learning and Teaching, 5(4), 557-581. 